\title{
(MIS)MATCHED PERCEPTIONS: GRADUATES AND EMPLOYERS' VIEWS ABOUT COMPETENCIES IN PROFESSIONAL ACTIVITIES
}

\author{
Sílvia Monteiro ${ }^{1}$, Leandro Almeida ${ }^{1}$, Adela Garcia-Aracil ${ }^{2}$ \\ ${ }^{1}$ Research Centre on Education, University of Minho (PORTUGAL) \\ ${ }^{2}$ INGENIO, CSIC-UPV, Polytechnic University of Valencia (PORTUGAL)
}

\begin{abstract}
The impact of globalization and rapid technological advancement drives to a new concept of working, which encourages continuous competencies' development, taking into account individuals' interests, personality and labour market opportunities. This new perspective implies, on one hand, high levels of self-knowledge and, on the other hand, an in-depth knowledge of the needs of employers' organizations. In the above context, this study aims to analyse the (mis)matches between the perceptions of mastery and utilization of graduates' competencies, taking graduates' and employers' perspectives. For such, three questions drive this study: How do graduates perceive their mastery and utilization of their competencies during professional activities? How do employers perceive graduates' mastery and utilization of their competencies? Are there mismatches among graduates and employers taking mastery vs utilization of competencies?

A sample of 180 graduates from four study fields (Economics, Social Sciences, Law and from Engineering) of a Portuguese public university participated in this study. From this group, 39 graduates reported to be unemployed, while 141 indicated to be employed at the moment of the inquiry. Sixty percent of the participants were female and the average age of the group of graduates was $24.89(S D=5.82)$. Ninety-eight employers were inquired, where $14 \%$ of them represented the public sector and $86 \%$ the private one. Fifty-three percent of the employers represented small and medium-size enterprises and $47 \%$ represented large-size companies. Data concerning graduates' perceptions were collected through an online survey distributed by email, approximately 18 months after completing their masters' degree. Data concerning employers' perceptions were also collected through an online survey, distributed by email.
\end{abstract}

The obtained results allow us to conclude there is several mismatches among graduates and employers' perceptions. In general, graduates have higher perceptions of mastery for transversal competencies than employers. However, in terms of technical competencies, employers consider graduates more competent than graduates think they are. This suggests that employers are satisfied in terms of the technical preparation of graduates, but not so satisfied in terms of transversal competencies. Furthermore, employers generally attribute higher relevance of competencies for professional practice than graduates do, with an implicit message that "everything is important". This might indicate some difficulty for employers to differentiate competencies in terms of relevance for professional activities. Taking the mismatches perceived within groups, graduates reported discrepancies for technical competencies (lower domain than professional requirement) and generic competencies (higher domain than professional requirement), while employers consider graduates' mastery of competencies are below professional requirement for all the transversal competencies analysed.

The observed mismatches suggest the need to strengthen the relationship between HE institutions and employers' organizations as a way to smooth graduates' labour market transition. An example of operationalization of this implication might be the inclusion of learning experiences integrated with professional realities, as a way to foster technical and transversal competencies among students.

Keywords: competencies; graduates; employers; (mis)matches; work transition.

\section{INTRODUCTION}

Over the last few years, some debate has been installed around the responsibility of Higher Education (HE) regarding graduates' employability. In Europe, this debate was particularly boosted by the Bologna process, which clearly defined the responsibility of the institutions to promote the employability of graduates. In the Yerevan Communiqué (2015), ministers defined employability as one out of four priorities for the period until 2018 , and emphasized the "(...) need to ensure that, at the 
end of each study cycle, graduates possess competences suitable for entry into the labour market which also enable them to develop the new competences they may need for their employability later in throughout their working lives" (p. 2). Thus, even if it can not to be unanimously perceived as its exclusive function, this perspective of higher education as a privileged way to access to the labor market leads to a political and scientific orientation commonly focused on matching competencies developed in higher education with those required in the labour market.

Simultaneously, the impact of globalization and rapid technological advancement drives to a new concept of working, which encourages continuous competencies' development, taking individuals' interests, personality and opportunities. This implies, on one hand, high levels of self-knowledge and, on the other hand, an in-depth knowledge of employers' needs. Current conceptualizations of employability are in line with this dynamic between competencies developed, self-efficacy perceptions and the ability to apply those competencies according with contextual demands at each moment [1], [2]. Hence, an individual would be employable to "the extent that he or she can parlay person factors effectively to negotiate environmental demands" [3, p. 16].

Several studies published in the last years around the mismatches of competencies derived from two large European projects: REFLEX (Research into Employment and Professional Flexibility) and CHEERS (Careers after Higher Education),(e.g., [4]-[6]). The overall results of these studies suggest that graduates perceived themselves prepared for job, although the professional requirements tend to be more demanding than the mastery of competencies. Other authors have conducted some other studies more regionally circumscribed, focusing exclusively around graduates' perceptions (e.g., [7]) or employers' perceptions (e.g., [8]). Taking that employability conceptualizations assume an holistic and integrative approach [3], [9], [10], and that mismatches between competencies acquired through $\mathrm{HE}$ and required by the labour market may be one of the reasons of higher vulnerabilities in terms of university-to-work transition [5], [11], empirical research integrating multiple perspectives from key informants bring an added value to the field. In the above context, this study aims to analyse the (mis)matches between the mastery and utilization of graduates' competencies, taking graduates' and employers' perspectives. For such, three questions drive this study: How do graduates perceive their mastery and utilization of their competencies during professional activities? How do employers perceive graduates' mastery and utilization of their competencies? Are there mismatches among graduates and employers taking mastery vs utilization of competencies?

\section{METHODOLOGY}

\subsection{Participants}

One hundred and eighty master graduates from four study fields (27\% from Economics, $32 \%$ from Social Sciences, 6\% from Law and 34\% from Engineering) from a Portuguese public university participated in this study. From this group, 39 graduates reported to be unemployed, while 141 indicated to be employed at the moment of the inquiry. Sixty percent of the participants were female and the average age of the group of graduates was $24.89(S D=5.82)$.

Ninety-eight employers were inquired, where $14 \%$ of them represented the public sector and $86 \%$ the private one, and $53 \%$ of the employers represented small and medium-size enterprises and $47 \%$ represented large-size companies. The economic activities represented were Agriculture $(n=1)$, Manufacturing $(n=6)$, Facilities $(n=16)$, ICT and Financial Services $(n=21)$, Professional and Administrative activities $(n=17)$, Health and Social Security $(n=24)$ and Education $(n=7)$. Six nonresponses were registered.

\subsection{Procedure}

Data concerning graduates' perceptions were collected through an online survey distributed by email, approximately 18 months after completing their masters' degree. Data concerning employers' perceptions were also collected through an online survey, distributed by email.

\subsection{Measure}

\subsubsection{Perceptions of competencies}

Participants were asked to evaluate graduates' mastery and utilization of competencies during their professional activity (in this latter case, only employed graduates were considered) in a 5-point Likert 
scale, ranging from 1 "very weak" to 5 "very strong". Technical competencies were presented to the participants as the technical training to perform a job; communication competencies refers to speaking and writing clearly and effectively; methodological competencies concerns to the ability to use tools and resources such as problem analysis, using information technologies or speaking a foreign language; interpersonal competencies refers to the ability to work and interact with others, and to lead, manage conflicts, work in a team and motivate others; participative competencies comprises initiative, autonomy, self-motivation, decision making, identification of opportunities, innovation and lifelong learning; organizational competencies concerns to the ability to organize tasks, to plan, collect and process information and to be attentive to detail; socio-emotional competencies refers to the ability to manage emotions and tolerate stress, self-confidence and self-control; and generic competencies comprises general knowledge, sense of citizenship and ethical awareness.

\section{RESULTS}

Regarding the perceptions of mastery of competencies presented in Table 1, the results show that, for the all competencies, graduates and employers scored higher the average point ( 2.5 values). Among unemployed graduates, organizations' competencies present the higher scores, while interpersonal competencies are the most positively rated among employed graduates. In employers' perspective, the graduates are more proficient in technical competencies. The Sheffé post hoc tests demonstrated that employers' perceptions are significantly different from both groups of graduates for technical, organization and interpersonal competencies ( $p=.000$, for the two comparisons). In the case of communication and participative competencies, the differences are solely present among employers and employed graduates ( $p=.006$ and $p=.000$, respectively). Concerning socioemotional competencies, the differences emerged between employed and unemployed graduates $(p=.016)$.

Table 1. Perceptions of mastery of competencies

\begin{tabular}{l|c|c|c|c|c}
\hline \hline & \multicolumn{2}{|c|}{ Graduates } & \multirow{2}{*}{ Employers } & \multirow{2}{*}{$\mathrm{F}$} & $p$ \\
\cline { 2 - 4 } & Unemployed & Employed & & \\
\cline { 2 - 4 } & Mean (SD) & Mean (SD) & Mean (SD) & & \\
\hline Technical & $3.36(.67)$ & $3.53(.78)$ & $4.11(.76)$ & 23.992 & .000 \\
\hline Communication & $3.95(.72)$ & $4.05(.71)$ & $3.68(.86)$ & 5.363 & .005 \\
\hline Methodological & $3.67(.62)$ & $3.78(.81)$ & $3.72(.71)$ & .395 & .674 \\
\hline Interpersonal & $3.95(.76)$ & $4.09(.71)$ & $3.57(.83)$ & 12.166 & .000 \\
\hline Participative & $3.85(.81)$ & $4.05(.72)$ & $3.67(.74)$ & 8.194 & .000 \\
\hline Organization & $4.13(.70)$ & $4.08(.66)$ & $3.60(.80)$ & 14.967 & .000 \\
\hline Socioemotional & $3.49(.85)$ & $3.87(.70)$ & $3.77(.72)$ & 4.241 & .015 \\
\hline Generic & $3.90(.82)$ & $3.92(.65)$ & $3.80(.64)$ & .491 & .612 \\
\hline \hline
\end{tabular}

Taking the perceptions of utilization of competencies presented in Table 2, and similarly to the perceptions of mastery, the obtained results show that the three groups recognize the all competencies as relevant for their professional activities (scores higher the average point of 2.5 values). Furthermore, it is evident that employers have higher perceptions of relevance of the all competencies, with the exception of organization competencies, which was scored slightly higher by graduates. Statistical differences between the two groups were significant for technical, communication, methodological, socioemotional and generic competencies, with higher perceptions of utilization by employers. 
Table 2. Perceptions of utilization of competencies

\begin{tabular}{|c|c|c|c|c|}
\hline \multirow{3}{*}{ Competencies } & \multicolumn{2}{|c|}{ Perceptions of utilization of competencies } & \multicolumn{2}{|c|}{$\begin{array}{c}\text { Between Group } \\
\text { differences }\end{array}$} \\
\hline & Graduates & Employers & \multirow[b]{2}{*}{$\mathrm{t}$} & \multirow[b]{2}{*}{$p$} \\
\hline & Mean (SD) & Mean (SD) & & \\
\hline Technical & $3.28(.97)$ & $4.47(.71)$ & 10.372 & .000 \\
\hline Communication & $4.00(.77)$ & $4.21(.70)$ & 2.123 & .035 \\
\hline Methodological & $3.72(.88)$ & $4.09(.72)$ & 3.427 & .001 \\
\hline Interpersonal & $4.04(.81)$ & $4.01(.82)$ & .170 & .865 \\
\hline Participative & $4.01(.75)$ & $4.05(.79)$ & .402 & .688 \\
\hline Organization & $4.13(.68)$ & $4.04(.75)$ & .956 & .340 \\
\hline Socioemotional & $3.89(.71)$ & $4.20(.67)$ & 3.397 & .001 \\
\hline Generic & $3.70(.79)$ & $3.99(.71)$ & 2.857 & .005 \\
\hline
\end{tabular}

Taking the values of the difference between perceptions of mastery and utilization of competencies presented in Table 3, it is possible to observe that the mismatch is more evident among graduates for technical competencies, with a negative value, which indicate an apparent insufficient domain for this competency, considering the level of requirement in professional activities. A significant and positive difference is evident for generic competencies, which indicates that the level of domain exceed the requirement in professional activities. Taking the employers' group, the differences are significant for the all competencies analysed, with the exception for technical competencies. In all the cases, the differences present negative values, which means that employers consider that graduates' mastery of these competencies is below the level of requirement during professional activity in their organizations.

Table 3. Differences between perceptions of mastery and utilization of competencies

\begin{tabular}{l|c|c|c|c|c|c}
\hline \hline $\begin{array}{l}\text { Perceptions of mastery } \\
\text { perceptions of utilization } \\
\text { of competencies }\end{array}$ & \multicolumn{3}{|c|}{ Graduates (employed) } & \multicolumn{3}{c}{ Employers } \\
\hline & Mean (SD) & $\mathrm{t}$ & $p$ & Mean (SD) & $\mathrm{t}$ & $p$ \\
\hline Technical & $.25(.90)$ & -5.429 & .000 & $-.34(.81)$ & -.877 & .382 \\
\hline Communication & $.04(.62)$ & .686 & .494 & $-.51(.88)$ & -5.618 & .000 \\
\hline Methodological & $.06(.70)$ & .956 & .341 & $-.37(.70)$ & -5.127 & .000 \\
\hline Interpersonal & $.05(.54)$ & 1,094 & .276 & $-.44(.78)$ & -5.377 & .000 \\
\hline Participative & $.04(.60)$ & .699 & .486 & $-.39(.70)$ & -5.375 & .000 \\
\hline Organization & $-.06(.61)$ & -1.239 & .218 & $-.46(.72)$ & -6.160 & .000 \\
\hline Socioemotional & $-.02(.70)$ & -.360 & .719 & $-.43(.67)$ & -6.264 & .000 \\
\hline Generic & $.21(.71)$ & 3.584 & .000 & $-.16(.57)$ & -2.811 & .006 \\
\hline \hline
\end{tabular}

\section{CONCLUSIONS}

The obtained results allow us to conclude there is several mismatches among graduates and employers' perceptions. In general, graduates have higher perceptions of mastery for transversal competencies than employers. However, in terms of technical competencies, employers consider graduates more competent than graduates think they are. This suggests that employers are satisfied in terms of the technical preparation of graduates, but not so satisfied in terms of transversal competencies. Furthermore, employers generally attribute higher relevance of competencies for professional practice than graduates do, with an implicit message that "everything is important". This 
might indicate some difficulty for employers to differentiate competencies in terms of relevance for professional activities. Taking the mismatches perceived within groups, graduates reported discrepancies for technical competencies (lower domain than professional requirement) and generic competencies (higher domain than professional requirement), while employers consider graduates' mastery of competencies are below professional requirement for all the transversal competencies analysed.

\section{LIMITATIONS AND IMPLICATIONS FOR FURTHER STUDIES}

Data collected for this study takes circumscribed samples from different study fields, which prevents any type of generalization of the data. Also, different measuring instruments are recommended for competencies' evaluation, such as ranking questionnaires, in order to avoid possible "overestimation of competencies" that might occur in the case of employers.

\section{PRATICAL IMPLICATIONS}

The observed mismatches suggest the need to strengthen the relationship between HE institutions and employers' organizations as a way to smooth graduates' labour market transition. An example of operationalization of this implication might be the inclusion of learning experiences integrated with professional realities, as a way to foster technical and transversal competencies among students.

\section{ACKNOWLEDGEMENTS}

This work was supported by the Fundação para a Ciência e a Tecnologia [SFRH/BPD/92331/2013] and by CIEd - Research Centre on Education, project UID/CED/01661/2019, Institute of Education, University of Minho, through national funds of FCT/MCTES-PT.

\section{REFERENCES}

[1] M. Yorke and P. Knight, Embedding employability into the curriculum. Learning and Employability Series 1. York: Higher Education Academy., 2004.

[2] L. D. Pool and P. Sewell, "The key to employability: developing a practical model of graduate employability," Educ. + Train., vol. 49, no. 4, pp. 277-289, 2007.

[3] M. Fugate, A. J. Kinicki, and B. E. Ashforth, "Employability: A psycho-social construct, its dimensions, and applications," J. Vocat. Behav., vol. 65, no. 1, pp. 14-38, Aug. 2004.

[4] J. Allen and R. van der Velden, "The flexible professional in the knowledge society: General Results of the REFLEX Project," Springer Netherlands, Dordrecht, 2011.

[5] A. Garcia-Aracil and R. van der Velden, "Competencies for young European higher education graduates: Labor market mismatches and their payoffs," High. Educ., vol. 55, no. 2, pp. 219-239, 2008.

[6] P. Teixeira, P. N. Teixeira, S. Cardoso, M. J. Rosa, and A. Magalhães, "Graduates' Perceptions about Labour Market Competencies: Does the Type of Institution and Programme Make a Difference," High. Educ. Policy, vol. 29, no. 1, pp. 109-129, 2016.

[7] M. Jusoh, M. Simun, and S. Choy Chong, "Expectation gaps, job satisfaction, and organizational commitment of fresh graduates," Educ. + Train., vol. 53, no. 6, pp. 515-530, Aug. 2011.

[8] S. McMurray and M. Dutton, "Employer demands from business graduates," Educ. + Train., vol. 58, no. 1, pp. 112-132, 2016.

[9] L. Guilbert, J. L. Bernaud, B. Gouvernet, and J. Rossier, "Employability: review and research prospects," Int. J. Educ. Vocat. Guid., vol. 16, no. 1, pp. 69-89, 2016.

[10] A. Forrier, M. Verbruggen, and N. De Cuyper, "Integrating different notions of employability in a dynamic chain: The relationship between job transitions, movement capital and perceived employability," J. Vocat. Behav., vol. 89, pp. 56-64, Aug. 2015.

[11] M. Teijeiro, P. Rungo, and M. J. Freire, "Graduate competencies and employability: The impact of matching firms' needs and personal attainments," Econ. Educ. Rev., vol. 34, pp. 286-295, 2013. 